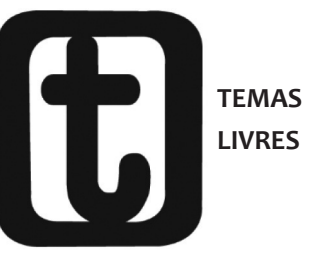




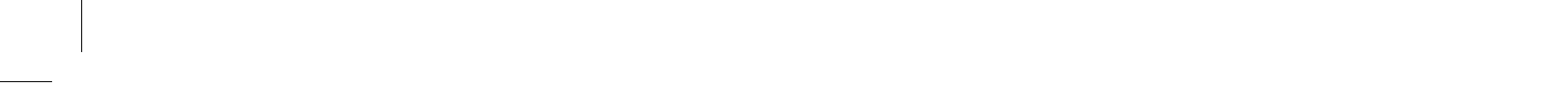




\title{
田
}

\section{ARTICULAÇÃO ENTRE ATORES DO SISTEMA DE GARANTIA DE DIREITOS}

\author{
ARTICULATION BETWEEN ACTORS OF THE RIGHTS GUARANTEE SYSTEM
}

\section{Aline Elisa Maretto Lang}

\section{RESUMO}

O objetivo deste artigo é apresentar como acontece a articulação entre dois atores do Sistema de Garantia de Direitos da Criança e do Adolescente, posicionados em eixos estratégicos, no estado do Espírito Santo entre os anos 2011-2014. Os dados apresentados são resultado de uma pesquisa qualitativa, obtidos através da realização de análise documental e entrevistas semiestruturadas. Os resultados alcançados indicam que, apesar das inovações trazidas pelo Estatuto da Criança e do Adolescente, esse Sistema ainda não atua de forma articulada e em parceria entre diferentes atores no território capixaba.

Palavras-chave: Sistema de Garantia de Direitos. Criança e Adolescente. Articulação em Rede.

\section{ABSTRACT}

The aim of this paper it is the presentation of how is the articulation between two actors of the system of guarantee of rights of the Child and Adolescent, positioned in strategic axes, at the Espírito Santo state during the years 2011-2014. The data presented are results of a qualitative research, obtained through documental analysis and semi structured interviews. The results indicate that despite the innovations introduced by the Statute of Children and Adolescents, this System still does not act in an articulated manner and partnership between different actors in the state of Espírito Santo.

1 Assistente social e mestre em política social pela Universidade Federal do Espírito Santo. 


\section{temporollis}

Keywords: System of Guarantee of Rights. Child and Adolescent. Articulation Through the Net.

Submissão - 05/05/2016

Aceite $-13 / 01 / 2017$

\section{Introdução}

Nas últimas décadas, os pressupostos que estabelecem as bases das políticas sociais destinadas às crianças e adolescentes no Brasil, vêm sofrendo mudanças significativas. Os anos 1980 e 1990, em especial, ofereceram condições favoráveis para que ocorressem mudanças importantes no lugar ocupado por esse público na sociedade e nas ações a eles direcionadas. A promulgação do Estatuto da Criança e do Adolescente (ECA), assim como a participação de diversos setores organizados da sociedade civil em defesa dos direitos da infância e adolescência, foram parte fundamental nessas mudanças. Vale lembrar, também, que todo esse movimento de luta por direitos ocorreu dentro do contexto de redemocratização do País em que a sociedade clamava pelo fim da ditadura militar.

O Estatuto sugere novos paradigmas de atenção à criança e ao adolescente, tendo como base preceitos de garantia de direitos estabelecidos pela Convenção Internacional dos Direitos da Criança, da qual o Brasil é signatário. Trata-se de uma legislação que introduz um novo paradigma no tratamento legal dado a infância e adolescência, pois reconhece esse segmento geracional como ser humano em desenvolvimento biopsicossocial e sujeito de direitos (MENDES, 2010). O Estatuto estabelece normas que visam à proteção da criança para o seu desenvolvimento integral e define que cabe a família, o Estado e a sociedade a promoção das condições adequadas para o desenvolvimento de todas as crianças e adolescentes, sem que haja qualquer tipo de discriminação ou distinção.

Trata-se de uma legislação que oferece condições legais para que ocorram verdadeiras mudanças na elaboração de políticas públicas para infância e juventude e na estrutura de funcionamento das instituições que atendem a esse público. O Estatuto possibilita uma nova relação entre o Estado e os usuários das políticas sociais, deixando de ser uma relação vertical, fundamentada no autoritarismo que, historicamente, caracterizou as relações entre as classes populares e o Estado no Brasil. 


\section{temporolis}

No entanto, de nada adiantaria a luta pelo reconhecimento dos direitos de crianças e adolescentes, o reconhecimento de que são sujeitos de direitos e pessoas em condição peculiar de desenvolvimento, se tais direitos não forem assegurados. Ou seja, é preciso promovê-los e protegê-los, através de instrumentos normativos, de instâncias públicas e de mecanismos em que todos tenham o mesmo objetivo (NOGUEIRA NETO, 2005).

Assim, visando à proteção integral de crianças e adolescentes, tem-se o Sistema de Garantia de Direitos da Criança e do Adolescente, que deve ser realizado através de uma política de atendimento, resultante da articulação de ações governamentais e não-governamentais da União, dos Estados, do Distrito Federal e dos municípios. Nesse sistema, a política de atendimento consiste em um conjunto de ações adotadas nas áreas das políticas sociais básicas, programas de assistência social e programas de proteção especial e jurídica para crianças e adolescentes.

Para que o Sistema de Garantias funcione como um mecanismo fluído e constante, é necessário que seus componentes (sociedade civil e governo) estejam integrados e articulados, partilhando responsabilidades e operando a partir de suas áreas de atuação visando um fim comum. Em conjunto, "as peças" que compõem o Sistema de Garantia de Direitos devem formular estratégias e ações que dialoguem com o cenário local (municípios, comunidades, centros de assistência, etc.) e com a política nacional.

Defende-se, assim, que:

[...] a ação objetivando a garantia de direitos — dada a incompletude do âmbito das instituições para enfrentamento da complexidade das questões a serem enfrentadas - demanda uma intervenção concorrente de diferentes setores, nas diversas instâncias da sociedade e do poder estatal. A efetividade e a eficácia dessa intervenção dependem de sua dinâmica, que, por mais complexa que seja sua arquitetura, não pode deixar de realizar uma articulação lógica intersetorial, interinstitucional, intersecretarial e, por vezes, intermunicipal. Essa articulação deve levar à composição de um todo organizado e relativamente estável, norteado por suas finalidades (BAPTISTA, 2012, p. 188).

O Sistema de Garantia de Direitos sugere um trabalho em rede 


\section{temporollis}

das instituições e dos atores envolvidos na proteção da infância e adolescência e uma ampla articulação entre o poder público e a sociedade civil. A procura da intersetorialidade entre as diferentes áreas do governo e da sociedade civil, otimizando espaços, serviços e competências é uma condição fundamental para que crianças e adolescentes sejam assistidos de maneira integral, de acordo com o estabelecido no Estatuto. Diante disso, o objetivo deste artigo é apresentar como tem acontecido a articulação entre dois atores sociais, posicionados em eixos estratégicos do Sistema de Garantia de Direitos de Crianças e Adolescentes, no estado do Espírito Santo. Intentamos, assim, apresentar dados que demonstram como tem acontecido, na prática, a articulação entre diferentes atores desse sistema no território capixaba.

Consiste em uma pesquisa de campo realizada no Conselho Estadual dos Direitos da Criança e do Adolescente do Espírito Santo (CRIAD) e na Secretaria de Estado de Assistência Social e Direitos Humanos (SEADH) ${ }^{2}$, entre os anos 2011 a 2014. ${ }^{3}$ Trata-se de um estudo inserido no campo das ciências sociais, em que o tipo de abordagem adotada foi a qualitativa.

Os dados empíricos aqui apresentados foram obtidos através de pesquisa documental e realização de entrevistas semiestruturadas. Os documentos analisados foram as atas das duas últimas gestões do Conselho (2011-2013 e 2013-2015). No total, foram analisadas 34 atas, sendo 18 de reuniões da gestão 2011-2013 e 16 da gestão 20132015. ${ }^{4}$ A leitura desses documentos possibilitou conhecer a dinâmica interna de funcionamento do Conselho, os temas ali discutidos, a menor frequência e participação do poder público nas reuniões, a baixa capacidade deliberativa do Conselho, as principais frentes de atuação

2 Esse levantamento condensa e atualiza diversos dados empíricos coletados pela autora para a realização da sua dissertação de mestrado "O Conselho Estadual dos Direitos da Criança e do Adolescente do Espírito Santo e sua relação com a Secretaria de Estado de Assistência Social e Direitos Humanos", orientada pela Profa. Dra. Márcia Smarzaro Siqueira e defendida na Universidade Federal do Espírito Santo (UFES), em 22 de setembro de 2015.

3 O recorte temporal definido para o estudo, 2011 a 2014, corresponde aos dois últimos mandatos do CRIAD (2011 a 2013 e 2013 a 2015), pois julgamos relevante avaliar a articulação do CRIAD com a SEADH em mandatos presididos por representantes do governo e da sociedade civil.

4 O número de atas analisadas da última gestão foi menor, pois analisamos somente as atas das reuniões que aconteceram até dezembro de 2014. 


\section{temporolis}

do CRIAD e a articulação e realização (ou não) de ações do Conselho em parceria com a Secretaria.

Além da pesquisa documental, também fizemos uso de entrevistas semiestruturadas para complementar as informações obtidas através dos documentos. Para isso, foram utilizados roteiros elaborados previamente, que permitiu que coletássemos dados específicos, visto que, esse tipo de entrevista, permite que o pesquisador tenha certa liberdade para adaptar suas questões a determinadas situações. Foram entrevistados 12 sujeitos, destes, 7 eram conselheiros dos direitos (sendo 4 da gestão 2013-2015 e 3 da gestão 2011-2013) e 5 servidores da SEADH. As entrevistas foram realizadas com os servidores que tinham algum envolvimento com a área da infância e adolescência na Secretaria. ${ }^{5}$

As reflexões apresentadas neste artigo têm a intenção de contribuir para a ampliação e qualificação dos debates sobre a importância da articulação do Sistema de Garantia de Direitos para assegurar os direitos de crianças e adolescentes, dando ênfase a uma realidade estadual. Para isso, nossa discussão se inicia apresentado o que é este sistema de garantias, seus preceitos legais, atores e importância, para - posteriormente - apresentar os dados obtidos na pesquisa de campo e algumas reflexões sobre a realidade observada.

\section{0 sistema de garantia de direitos da criança e do adolescente}

O Sistema de Garantia de Direitos da Criança e do Adolescente é uma maneira de materializar a Doutrina da Proteção Integral, assegurada pelo Estatuto. Consiste em dar garantias legais para que toda criança e adolescente tenham direito ao pleno desenvolvimento físico, psicológico e social.

A estruturação desse sistema, para Baptista (2012, p. 190):

[...] não contemplaria uma política setorial apartada, mas iria ressaltar a perspectiva de integralidade da ação, que deveria cortar transversal e intersetorialmente todas as políticas públicas, incluindo nesse sistema o cam-

5 Para a realização das entrevistas e a posterior divulgação de suas informações, todos os entrevistados assinaram um Termo de Consentimento Livre e Esclarecido, que elucidava os objetivos e procedimentos metodológicos da pesquisa. 


\section{temporolis}

po da 'administração da justiça', ao lado do campo das 'políticas de atendimento'.

É necessário deixar claro, porém, que o Sistema de Garantia de Direitos "[...] se operacionaliza mais como um "sistema estratégico' do que propriamente como um 'sistema de atendimento direto'." (NOGUEIRA NETO, 2005, p. 14). Ou seja, trata-se de uma rede de proteção aos direitos da infância e adolescência composta por diversas instituições do governo e da sociedade civil organizada.

$\mathrm{Na}$ implementação desse sistema há a necessidade de refletir as ações, assim como as inter-relações institucionais referentes às diferentes situações em que crianças e adolescentes precisam de proteção, buscando a garantia de seus direitos, estabelecendo com clareza os papéis dos diversos atores sociais responsáveis pela efetivação do ECA, posicionando-os em eixos estratégicos e inter-relacionados. Não podemos deixar de lembrar, também, da importância de fortalecer o controle externo da sociedade civil sobre essa rede de proteção social (BAPTISTA, 2012).

Em 2006, a Secretaria Especial dos Direitos Humanos e o Conselho Nacional dos Direitos da Criança e do Adolescente (CONANDA), visando fortalecer e apoiar essa rede de proteção, em deliberação conjunta, assinaram a Resolução $n^{\circ}$. 113, de 16 de abril. Tal resolução dispõe sobre os parâmetros para institucionalização e fortalecimento desse sistema, definindo - em seu artigo $2^{\circ}$ - como competência do Sistema de Garantia de Direitos:

[...] promover, defender e controlar a efetivação dos direitos civis, políticos, econômicos, sociais, culturais, coletivos e difusos, em sua integralidade, em favor de todas as crianças e adolescentes, de modo que sejam reconhecidos e respeitados como sujeitos de direitos e pessoas em condição peculiar de desenvolvimento; colocando-os a salvo de ameaças e violações a quaisquer de seus direitos, além de garantir a apuração e reparação dessas ameaças e violações. (CONANDA, 2006).

O enfretamento dos atuais níveis de desigualdades e iniquidades que se manifestam nas formas de discriminação, exploração e violências, sustentadas por razões de classe social, gênero, raça/etnia, orientação sexual, deficiência e localidade regional, também são tarefas para os atores que compõem esse sistema de garantias. Trata-se de questões que dificultam consideravelmente a concretização plena 


\section{tempordilis}

dos direitos humanos do público infanto-juvenil, assegurados nas diversas legislações vigentes e que, devido a isto, devem ser superadas. (CONANDA, 2006).

A Resolução $n^{\circ} 113$ de 2006 do CONANDA estabelece que a configuração do Sistema de Garantia de Direitos da Criança e do Adolescente se estrutura a partir da articulação e integração em rede das instâncias públicas governamentais e da sociedade civil, a partir de três eixos estratégicos: de defesa dos direitos humanos, promoção dos direitos humanos, e controle da efetivação dos direitos humanos. (CONANDA, 2006). Essa divisão é importante para compreensão do lugar e do papel de cada órgão/instituição nesse sistema e, por conseguinte, o papel dos diferentes atores sociais dessa rede de proteção no Espírito Santo (ES).

É preciso deixar claro, porém, que "[...] isso não significa que determinado órgão público ou entidade social só exerça exclusivamente funções em uma linha estratégica." (NOGUEIRA NETO, 2005, p. 15). Ao exercer determinadas funções cada um dos atores desse sistema exerce, preponderantemente, um tipo de estratégia de garantia de direitos, mas, podem, também, em caráter secundário, executar estratégias de outros eixos.

O eixo de defesa dos direitos humanos consiste em zelar pela garantia do cumprimento dos direitos das crianças e dos adolescentes, através de intervenções onde e quando houver ameaças ou violações desses direitos. Esse eixo caracteriza-se pela garantia do acesso à justiça, ou seja, pelo recurso às instâncias públicas e mecanismos jurídicos de proteção legal dos direitos humanos. ${ }^{6}$ (CONANDA, 2006).

Nesse eixo estão situadas as ações judiciais realizadas nas Varas da Infância e da Juventude; nas Varas Criminais especializadas; nos Tribunais do Júri; nas Comissões Judiciais de Adoção; nos Tribunais de Justiça; nas Corregedorias Gerais de Justiça, das Coordenadorias da Infância e da Juventude dos Tribunais de Justiça. Nele ainda estão si-

6 O Estatuto da Criança e do Adolescente assegura o acesso à justiça a todas as crianças e adolescentes quando ameaçados ou quando têm violados seus direitos. Assegura o acesso à Defensoria Pública, ao Ministério Público e ao Poder Judiciário (art.141); o acesso à Polícia Judiciária e Técnica e aos demais órgãos públicos e entidades sociais de defesa de direitos (p. ex.: Ordem dos Advogados do Brasil, órgãos de assistência judiciária, Centros de Defesa) e aos Conselhos Tutelares. (BRASIL, 1990). 


\section{temporalis}

tuadas as ações público-ministeriais de competência das Promotorias de Justiça, dos Centros de Apoio Operacional, das Procuradorias de Justiça, das Procuradorias Gerais de Justiça, das Corregedorias Gerais e do Ministério Público. Somam-se ainda a esse eixo as ações das defensorias públicas, dos serviços de assessoramento jurídico e de assistência judiciária, da Advocacia Geral da União, das Procuradorias Gerais dos Estados. Também fazem parte dessa rede de proteção, nesse eixo de defesa, as Ouvidorias e a Policia Civil Judiciária, até mesmo a Polícia Técnica e a Polícia Militar. (BAPTISTA, 2012). Por fim, é preciso acrescentar que, no âmbito da sociedade civil, participam do eixo da defesa de direitos os conselhos tutelares, as entidades sociais de defesa de direitos humanos encarregadas de oferecer proteção jurídicosocial.

Já o eixo de promoção dos direitos humanos compreende as políticas sociais básicas destinadas à população infanto-juvenil e às suas famílias. Ou seja, operacionaliza-se através do desenvolvimento da "política de atendimento dos direitos da criança e do adolescente", conforme estabelecido no artigo 86 do ECA. (CONANDA, 2006).

Consiste em um eixo que se situa na área da formulação e operação das políticas sociais, onde são proporcionadas as condições materiais para que sejam respeitadas a liberdade, a integridade e a dignidade oferecendo condições para que as necessidades básicas sejam atendidas.

Nesse eixo de defesa, devem ser realizadas as ações que tem como fundamento os diagnósticos situacionais e institucionais e diretrizes gerais que se concretizam, sobretudo, com a criação, implementação e qualificação/fortalecimento dos serviços e atividades; dos programas e projetos específicos e próprios; assim como de políticas sociais em geral. Essas ações devem ser operacionalizadas pelas entidades de atendimento governamentais e não governamentais. (BAPTISTA, 2012).

A operacionalização da política de atendimento dos direitos da criança e do adolescente ocorre através de três tipos de programas, serviços e ações públicas: a) Serviços e programas das políticas públicas, especialmente das políticas sociais direcionadas a esse segmento geracional; b) Serviços e programas de execução de medidas de proteção de direitos humanos; e c) Serviços e programas de execução de medidas socioeducativas e assemelhadas. (CONANDA, 2006). 


\section{temporolis}

A consolidação desse eixo se dá por meio do desenvolvimento de uma política de atendimento, que integra o âmbito maior da política de promoção e de proteção dos direitos humanos. É uma política especializada, a qual deverá desenvolver-se, estrategicamente, de maneira transversal e intersetorial, articulando todas as políticas sociais (infraestruturantes, institucionais, econômicas e sociais) e integrando suas ações em favor da garantia daqueles direitos. (BAPTISTA, 2012, p.194-195).

É importante destacar, ainda, que na descentralização política e administrativa das ações, a esfera federal fica incumbida da coordenação nacional e a edição das normas gerais. Já a coordenação e a operação de seus respectivos programas cabem às esferas estaduais, distrital e municipal, assim como às entidades sociais. Nessa rede de proteção aos direitos de crianças e adolescentes também foram abertos espaços que possibilitam a participação da população na formulação das políticas, assim como no controle das ações em todos os níveis, através das organizações representativas. (BAPTISTA, 2012). Verifica-se, assim, que esse eixo é composto por diversas instituições, tanto governamentais como não governamentais, que são responsáveis pela formulação e operação das políticas sociais, tendo atribuições diferenciadas de acordo com o nível de gestão (federal, estadual e municipal).

A Secretaria de Estado de Assistência Social e Direitos Humanos é um dos órgãos do governo do estado do Espírito Santo que está inserido no eixo de promoção dos direitos de crianças e adolescentes. A SEADH tem um papel fundamental no desenvolvimento e execução da política de assistência social no ES, dentre elas as destinadas ao público infanto-juvenil. Enquanto órgão gestor do Sistema Único de Assistência Social (SUAS) no estado, é a Secretaria responsável pela regulamentação, formulação e implementação da Política Estadual de Assistência Social no território capixaba, observando as deliberações dos mecanismos de controle social legalmente instituídos. (ESPÍRITO SANTO, 2014).

Sendo o órgão gestor do SUAS no estado do Espírito Santo, na rede de proteção aos direitos da infância e adolescência, a SEADH tem o papel de coordenar e - em alguns casos - operacionalizar os serviços e programas das políticas públicas, tanto em âmbito da proteção 


\section{temporollis}

social básica ${ }^{7}$ como na proteção social especial ${ }^{8}$ direcionadas às famílias, assim como às crianças e adolescentes. Além de coordenar os serviços e programas de execução de medidas de proteção de direitos humanos. Parte dos serviços e programas de execução de medidas socioeducativas e assemelhadas, também é coordenada e operacionalizada pela SEADH, no âmbito da proteção social especial de média e alta complexidade9, ficando a cargo da Secretaria de Estado de Justiça a execução das medidas socioeducativas que preveem a privação de liberdade do adolescente infrator.

Observa-se, assim, que no âmbito da assistência social - na rede de proteção aos direitos da infância e adolescência - a SEADH atua tanto na prevenção das vulnerabilidades e riscos sociais, ao coordenar as ações de proteção social básica e de proteção aos direitos humanos, quanto na recuperação de vínculos familiares e comunitários, através das ações da proteção social especial de média e alta complexidade. A amplitude das ações executadas pela Secretaria demonstra a sua importância para esse Sistema de Garantia de Direitos no estado do ES.

Por fim, o terceiro eixo do sistema de garantias consiste no eixo de controle da efetivação dos direitos humanos em que é tratado da participação da sociedade na formulação e acompanhamento das políticas sociais voltadas para o atendimento de crianças e adolescentes, através de ações de organizações da sociedade civil ou por meio

7 De acordo com PNAS, a assistência social está organizada em Proteção Social Básica (PSB) e Proteção Social Especial (PSE) de média e alta complexidade (MINISTÉRIO, 2004). A Proteção Social Básica tem como objetivo prevenir as situações de risco e vulnerabilidades sociais, por meio do desenvolvimento de potencialidades e aquisições e através do fortalecimento de vínculos sociais e comunitários.

8 A Proteção Social Especial consiste em uma modalidade de atendimento assistencial designada a famílias e indivíduos que estão em situação de risco pessoal e social, decorrentes de abandono, maus-tratos físicos e, ou, psíquicos, abuso sexual, uso de substâncias psicoativas, cumprimento de medidas socioeducativas, trabalho infantil, situação de rua, dentre outras (MINISTÉRIO, 2004). Os serviços da PSE são caracterizados de acordo com os níveis de complexidade, sendo subdividido em média e alta complexidade.

9 Os serviços de média complexidade são aqueles que oferecem atendimento às famílias e indivíduos com direitos violados, mas que os vínculos familiares e comunitários ainda não foram rompidos. Já os serviços de alta complexidade são aqueles que garantem a proteção integral (moradia, alimentação, higienização e trabalho protegido) para famílias e indivíduos que se encontram sem referência e/ ou em situação de ameaça, que precisam ser retirados de seu núcleo familiar e/ou comunitário (MINISTÉRIO, 2004). 


\section{temporalis}

das instâncias formais de participação estabelecidas na lei, nesse caso os Conselhos dos Direitos.

O controle social do direito é a área preferencial e peculiar das organizações da sociedade civil organizada para que seja exercitado esse controle. Além dessas organizações, esse eixo atua também através das instâncias públicas colegiadas próprias, tais como os conselhos dos direitos, conselhos setoriais de formulação e controle de políticas públicas e órgãos e poderes de controle interno e externo de fiscalização contábil. ${ }^{10}$ No caso dos conselhos, tem-se ainda a garantia da paridade na participação entre órgãos governamentais e de entidades sociais. (BAPTISTA, 2012).

É nesse eixo que o Conselho Estadual dos Direitos da Criança e do Adolescente do Espírito Santo está inserido. É nele que o CRIAD deve exercitar a sua função seminal, que o capacita e legitima para a sua inserção institucional nos outros eixos estratégicos desse sistema, tornando-o imprescindível para o fortalecimento da democracia. Seu objetivo é implementar a política de atenção a esse segmento geracional enquanto uma ação integrada, uma vez que as políticas correspondentes precisam ser articuladas as demais políticas setoriais para contemplar a normativa da proteção integral.

\section{A articulação entre atores do sistema de garantia de direitos no território capixaba}

O funcionamento do Sistema de Garantia de Direitos prevê a articulação entre os seus diferentes atores para que crianças e adolescentes sejam assistidos de maneira integral, conforme preconizado pelo Estatuto. Tendo clareza dos papéis assumidos pelo CRIAD e pela SEADH nessa rede de proteção, em âmbito estadual, procuramos identificar se o Conselho e a Secretaria realizaram ações em parceria no período de 2011 a 2014. Verificar se existiu ou não essa parceria é uma das maneiras de analisar como esses dois atores sociais do sistema de garantias têm se relacionado e se esse sistema tem articulado seus eixos estratégicos em busca da proteção e da garantia de direitos de crianças e adolescentes no estado do Espírito Santo.

10 Esses órgãos estão definidos nos artigos 70, 71, 72, 73, 74 e 75 da Constituição Federal. (BRASIL, 1988). 


\section{temporollis}

Os dados coletados para esta análise foram obtidos por meio das entrevistas com os conselheiros e servidores da SEADH e análise das atas das reuniões ordinárias do Conselho, em que buscamos verificar se nas plenárias do CRIAD eram pautadas as ações em conjunto com a Secretaria.

Ao questionar os conselheiros do CRIAD se o Conselho realizou ou realiza ações em parceria com a SEADH, cinco deles responderam que sim, um afirmou que não e um alegou não saber. Já nas entrevistas com os servidores da SEADH, três afirmaram que são realizadas as ações em parceria e os outros dois alegam que não. Observa-se, assim, que não existe consenso entre os conselheiros e, do mesmo modo, entre os servidores da secretaria quanto à realização de ações em conjunto. Porém, na leitura das atas do CRIAD, ressaltamos que em nenhuma delas foi apontando a realização de ações em conjunto com a Secretaria. A SEADH aparece nas discussões do Conselho apenas para o fornecimento de infraestrutura para a realização de ações pontuais. Tais dados revelam uma divergência entre o que foi dito pelos entrevistados e o que está registrado nos documentos do Conselho, indicando a necessidade de análise de outros fatores que poderiam caracterizar essa articulação.

Utilizamos a pesquisa documental e as entrevistas para identificar quais ações teriam sido realizadas em conjunto a fim de compreender o tipo de parceria que alguns conselheiros e servidores afirmaram existir. Verificamos, a partir dos dados coletados, que essas ações estão restritas a organização das conferências e seminários, capacitações pontuais de conselheiros e seleção de projetos para recebimento de recursos do Fundo para a Infância e Adolescência. Esses dados indicam que não há uma frequência na realização de atividades entre o CRIAD e a SEADH em questões referentes à garantia e defesa de direitos de crianças e adolescentes no ES. O que se observa é que em ações nas quais o CRIAD não tem condições de realizar sozinho, muitas vezes por falta de recursos humanos e financeiros, ele solicita apoio da Secretaria.

Ao verificar como são realizadas essas parcerias, a maneira como o Conselho e a SEADH organizam suas ações, fica ainda mais clara a casualidade dos encontros. Observamos que a SEADH só é demandada pelo Conselho para resolver questões operacionais das ações realizadas, oferecendo suporte técnico e material. No entanto, não foram mencionados pelos entrevistados momentos em que $o$ 


\section{tempordilis}

Conselho e a Secretaria se reúnem para debater, de maneira ampliada, uma determinada ação.

Assim como Baptista (2012, p. 188) acreditamos que "[...] um princípio norteador da construção de um sistema de garantia de direitos é a sua transversalidade." O que observamos na prática é que o CRIAD ao se articular com a SEADH apenas para o fornecimento de infraestrutura, não debatendo, refletindo e propondo ações visando garantir os direitos de crianças e adolescentes, terá dificuldades para alcançar os objetivos estabelecidos no Sistema de Garantia de Direitos. Os diferentes aspectos desse sistema deveriam ser reciprocamente relacionados, assim, as reflexões, os debates e as propostas de ações, no sentido de garanti-los, somente alcançarão a eficácia desejada se forem tomadas integradamente como uma maneira de fortalecer as iniciativas em diferentes dimensões. (BAPTISTA, 2012).

Na prática, um exemplo de uma articulação importante entre o Conselho e a Secretaria foi à tentativa de formulação do Plano Estadual de Convivência Familiar e Comunitária. Na construção desse Plano deveriam ser observados os diferentes aspectos da realidade das crianças e adolescentes capixabas a partir de debates, reflexões e propostas de ações. A comissão de políticas públicas do Conselho chegou a tentar realizar uma articulação junto a Secretaria para a realização de reuniões para debater as questões referentes ao Plano e fazer a sua formulação. No entanto, de acordo com os Conselheiros e Servidores entrevistados, essa articulação não teve continuidade e o Plano ainda não foi formulado.

Não podemos deixar de ressaltar que, em nossa sociedade, a garantia de direitos é de responsabilidade de distintas instituições que atuam de acordo com a sua competência. Entretanto, historicamente, tais ações têm sido focalizadas e fragmentadas, não garantindo um projeto comum que permita a efetividade de sua abrangência e uma eficácia maior no alcance de seus objetivos principais. (BAPTISTA, 2012). As observações feitas em campo demonstram que esses traços históricos estão longe de serem superados. Nesse sentido, Suguihiro (2000, p. 11) já alertava sobre a dificuldade dos conselhos de "[...] atuar no campo das ações propositivas, desqualificando-se enquanto instrumento de interlocução e controle das ações governamentais."

As dificuldades enfrentadas para a realização das ações em conjunto também foram analisadas para que pudéssemos ter indícios 


\section{temporollis}

dos fatores que podem estar dificultado essa articulação. As principais dificuldades relatadas consistiram nas dificuldades orçamentárias, que a SEADH sempre alega - de acordo com os conselheiros entrevistados -, e a falta de recursos humanos no Conselho. Somado a essas questões, um dos servidores entrevistados fez questão de destacar a falta de diálogo como fator dificultador dessa articulação.

A dificuldade de diálogo entre a Secretaria e o CRIAD é um fator que dificulta não só a execução de ações em parceria, como também a própria relação da SEADH com o CRIAD. Como falar de uma relação sem pensarmos no diálogo entre seus principais atores? Essa questão se torna ainda mais preocupante quando lembramos que a SEADH tem representantes no Conselho e, durante uma gestão inteira, foi presidido por um representante da SEADH. Diante disso, somos instigados a questionar como os representantes da Secretaria no Conselho têm atuado para facilitar e melhorar o diálogo entre eles?

Também não foram mencionados, nas falas dos sujeitos entrevistados, mecanismos estatais que facilitem essa articulação. O que demonstra que ainda parece existir uma falta de instrumentos de acompanhamento governamental que instigue a integração entre 0 Conselho e os setores governamentais. Nascimento (2012, p. 85) defende que "[...] caberia ao governo, e aos seus representantes, estimular essa integração." De acordo com o autor:

Ainda que não exista essa articulação, o governo pode ser um agente facilitador para essa integração. Isso tem relação com a capacitação dos conselheiros governamentais para estimular a integração, mas também tem ligação com a estrutura que o governo disponibiliza para apoio ao conselho. (NASCIMENTO, 2012, p. 85).

Assim como Nascimento (2012), Cruz (2000) também acredita na importância da capacitação dos conselheiros como uma ferramenta para superar a fragmentação que existe entre as ações do governo e dos Conselhos. A autora ainda destaca a importância de se pensar em ações intersetoriais que articulem os Conselhos com diversos setores da política pública, para ela:

As capacitações devem enfocar uma abordagem intersetorial das políticas sociais, evitando a fragmentação. Não há como pensar a questão da criança desnutrida, sem pensar em uma estratégia de geração de renda que envolve a saúde, educação, assistência social e outras 


\section{tempordils}

áreas que tem programas voltados para esse segmento. As diversas secretarias ou departamentos da prefeitura e seus respectivos conselhos devem pensar todas as necessidades do cidadão, pois o grande desafio é a articulação das políticas públicas para a obtenção de resultados efetivos na vida de todos. (CRUZ 2000, p. 77).

Concordamos com Santos (2012, p. 245) que "[...] a integralização de políticas para infância e adolescência é vital para a solução de muitos dos problemas sofridos pelas crianças e adolescentes deste país." A ação de integralizar as políticas para infância e adolescência, embora não seja, claramente, uma das atribuições dos conselhos, é uma consequência do princípio da proteção integral a esse segmento geracional. Como já mencionado anteriormente, a articulação entre os diferentes atores que compõe essa rede de proteção é fundamental para assegurar a proteção integral de crianças e adolescentes e é um dos princípios do Sistema de Garantia de Direitos.

Também avaliamos importante identificar, na opinião de conselheiros e servidores, a relevância da realização de atividades e ações em parceria e a articulação entre o Conselho e a Secretaria. Nesse ponto, 9 dos 12 entrevistados afirmaram que é essencial a realização dessas ações e como elas são positivas, demonstrando clareza da necessidade que se tem de atuar em rede para garantir o cumprimento do Estatuto.

Os servidores entrevistados destacaram que a realização dessa articulação seria positiva, pois tem potencial para provocar e atualizar a secretaria sobre os debates que vêm sendo realizados no Conselho sobre a realidade da infância e adolescência no território capixaba. Além disso, alguns deles têm clareza que a política para esse segmento geracional deve ser proposta e executada de forma articulada. Inclusive reforçaram que o CRIAD, enquanto formulador da política, deveria se articular com os órgãos que fazem à execução do atendimento para que, a partir do momento que existir essa articulação, eles consigam juntos perceber as dificuldades enfrentadas para a sua efetivação, assim como as demandas desse público e os avanços já obtidos.

Constata-se, a partir da pesquisa, que o reconhecimento, por parte dos conselheiros e dos servidores da SEADH, da importância da atuação em parceria, fortalecendo a rede de proteção e de garantia dos direitos da criança e do adolescente no ES não tem sido suficiente 


\section{temporollis}

para o desenvolvimento de ações conjuntas. Nesse sentido, verificase que ainda são muitos os desafios postos a atuação do CRIAD e da Secretaria.

Somado a todos os desafios que não postos diariamente para a atuação do conselho e da secretaria, não poderíamos deixar destacar a conjuntura econômica e social na qual eles estão inseridos. No contexto neoliberal passa a existir uma política social adequada a esta realidade em que se observa a perda do seu sentido de solidariedade, pacto social e reforma democrática e redistributiva. O que vivenciamos agora é "[...] a conjugação de políticas seletivas e focalizadas para a 'horda' [...], combinadas à transformação em mercadoria de determinados serviços, pela via da privatização, voltados aos que podem pagar [...]." (BEHRING, 2008, p. 41-48). Por outro lado, tem-se a descentralização, outra tendência deste período, que pode ser visualizada em duas direções. A primeira delas é o repasse de responsabilidades para os municípios. Enquanto a segunda, consiste em uma maior ênfase dada as Organizações Não-Governamentais - não lucrativas - e no voluntariado, ambas situadas no campo da sociedade civil, um espaço virtuoso, eficaz e solidário, desresponsabilizando o Estado que é caracterizado como ineficiente, perdulário e paternalista. (BEHRING, 2008).

Ao refletir sobre as consequências desse contexto para a proteção social e suas repercussões para a infância e juventude, Manfroi (2005, p. 6) afirma que:

A agenda neoliberal propõe à contra-reforma do Estado em oposição aos direitos sociais assegurados na Constituição, a subsidiariedade em contraposição à universalização das políticas sociais, a focalização contrária à doutrina da proteção integral (essa doutrina propõe uma política de atendimento baseada na articulação entre políticas sociais básicas, assistenciais e de proteção especial), a centralização das decisões no nível federal operando a partir de programas pré-estabelecidos e que apenas executados pelos municípios.

Assim, em um contexto de contrarreforma do Estado o que estamos verificando é a predominância de políticas sociais cada vez mais focalizadas e a centralização das decisões em nível federal, restando aos Estados e municípios a simples execução de projetos já definidos pelo governo federal. Esse modelo é desfavorável à doutrina da proteção integral que prevê um Sistema de Garantia de Direitos 


\section{temporalis}

baseado na articulação entre diversos atores e políticas sociais.

Nesse contexto, estamos perante um grande desafio que “[...] é criar estratégias para recompor a totalidade da política social. Os conselhos deveriam ter essa tarefa, que transcende a política específica setorial." (TEIXEIRA, 2000, p. 45).

\section{Considerações Finais}

Ao analisar as diversas variáveis que caracterizam a articulação entre o CRIAD e a SEADH no desenvolvimento de ações em conjunto, constatamos que a articulação entre esses atores do Sistema de Garantia de Diretos no estado do Espírito Santo ainda é muito fragilizada. De modo geral, só existe uma articulação em rede entre eles para o desenvolvimento de ações pontuais e que, na maioria dos casos, acontece apenas para discussão de fatores referentes à infraestrutura e orçamento.

Outro aspecto importante, inclusive já observado por Dagnino (2002), é que uma das características, frequentemente adotadas pelos espaços públicos que se formam no interior do Estado, é de isolamento em relação aos órgãos da estrutura administrativa. Para a autora, esses espaços “[...] a cabam se constituindo como 'ilhas' separadas, em 'institucionalidades paralelas', conservadas à margem e com difícil comunicação com o resto do aparato estatal." (DAGNINO, 2002, p. 147).

A fragilidade nessa articulação do Conselho com o Governo retoma as discussões sobre a tradicional fragmentação da discussão das políticas públicas, reforçando o caráter setorial nas discussões dos Conselhos (PONTUAL, 2008) indicando, assim, que essa é uma dificuldade vivenciada pelos Conselhos há anos. Para o enfrentamento e superação dessa realidade, concordamos com Teixeira (2000) para que os Conselhos efetivamente se constituam como elementos de uma nova institucionalidade democrática, é preciso que a sociedade civil e seus representantes políticos e sociais estabeleçam um projeto político global e estratégico que seja referência para as deliberações de políticas sociais, caso contrário, seria muito difícil impedir a fragmentação destas políticas postas em vigor pelo governo.

A criação de espaços e maneiras de articulação entre os con- 


\section{temporollis}

selhos e destes com o governo, parece ser um caminho importante na perspectiva de integração da política. (PONTUAL, 2008). No caso do CRIAD, especificamente, os representantes da SEADH no Conselho poderiam ser "ponte" para que essa articulação acontecesse entre eles. Assim como Raichelis (2000, p. 46), acreditamos que, "[...] uma grande tarefa é pensar estratégias de integração e articulação entre os conselhos, criar agendas comuns e fóruns mais amplos que contribuam para superar a segmentação das políticas sociais." A mudança no padrão de gestão e dos procedimentos do governo, visando uma melhor articulação das políticas e programas, também é fundamental para estimular uma maior articulação dos conselhos e melhorar a integração das políticas e programas. (PONTUAL, 2008).

Por fim, é possível afirmar que muitos avanços já foram obtidos na defesa dos direitos de crianças e adolescentes, porém, ainda há muito a se avançar. A articulação e fortalecimento do Sistema de Garantia de Direitos é uma das maneiras de continuarmos avançando na luta pela garantia e defesa dos direitos desse segmento geracional. É fundamental continuarmos insistindo nesse processo, sem perder de vista a perspectiva de mudança em busca de uma sociedade democrática que estimule as lutas coletivas em favor dos direitos da infância e adolescência.

\section{REFERÊNCIAS}

BAPTISTA, Myrian Veras. Algumas reflexões sobre o sistema de garantia de direitos. Serviço Social e Sociedade, São Paulo, n 109, p. 179-199, 2012.

BEHRING, Elaine Rossetti. Brasil em contra-reforma: desestruturação do estado e perda de direitos. 2. ed. São Paulo: Cortez, 2008.

BRASIL. Constituição (1988). Constituição [da] República Federativa do Brasil. Brasília: Senado Federal, 1988.

. Lei n. 8.069, de 13 de julho de 1990. Dispõe sobre o Estatuto da Criança e do Adolescente e dá outras providências. Diário Oficial da União, Poder Executivo, Brasília-DF, 27 set. 1990. Disponível em: < http://www.planalto.gov.br/ccivil_03/leis/L8069.htm> Acesso em: 19 
fev. 2014 .

CONSELHO NACIONAL DOS DIREITOS DA CRIANÇA E DO ADOLESCENTE. Resolução n.113, de 19 de abril de 2006. Dispõe sobre o Sistema de Garantia de Direitos da Criança e do Adolescente. Diário Oficial da União, Poder Executivo, Brasília-DF, 13 abr. 2006. Disponível em: <www.mprs.mp.br> Acesso em: 19 fev. 2014.

CRUZ, Maria do Carmo Meirelles. Desafios para o funcionamento eficaz dos conselhos. In: CARVALHO, Maria do Carmo A. A.; TEIXEIRA, Ana Cláudia C. (Orgs.). Conselhos gestores de políticas públicas. São Paulo: Instituto Pólis, 2000.

DAGNINO, Evelina. Democracia, teoria e prática: a participação da sociedade civil. In: PERISSOTTO, Renato; FUKS, Mario. (Orgs.). Democracia: teoria e prática. Rio de Janeiro: Fundação Araucária, 2002.

ESPÍRITO SANTO (Estado). Secretaria de Estado de Assistência Social e Direitos Humanos. Relatório de gestão 2013. Vitória: SEADH, 2013.

MANFROI, Vânia Maria. Política social para crianças e adolescentes no governo Lula: mudança ou continuidade?. In: CONGRESSO BRASILEIRO DE SOCIOLOGIA, 12., 2005. Belo Horizonte-MG. Anais eletrônico... Belo Horizonte-MG: SBS, 2005. Disponível em: < http://www. sbsociologia.com.br/portal/index.php?option=com_docman\&task=cat_view\&gid=64\&ltemid=171> Acesso em: 21 mar. 2014 .

MENDES, Élio Braz. Direitos humanos e o estatuto da criança e do adolescente comentários do Livro I, parte geral, artigos $1^{\circ}$ ao 85 . In: MIRANDA, Humberto (Org.). Crianças e adolescentes: do tempo da assistência à era dos direitos. Recife: Ed. Universitária da UFPE, 2010.

MINISTÉRIO DO DESENVOLVIMENTO SOCIAL E COMBATE A FOME. Conselho Nacional de Assistência Social. Resolução $n^{\circ}$. 145, de 15 de outubro de 2004. Dispões sobre a Política Nacional de Assistência Social. Diário Oficial da União, Poder Executivo, Brasília-DF, 16 out. 2004. 


\section{temporollis}

Disponível em: <https://www.legisweb.com.br/legislacao/?id=101000> Acesso em: 19 fev. 2014.

NASCIMENTO, Anderson Rafael. É possível conselhos tão diferentes encontrarem aquilo que lhes é comum? Um olhar sobre a interface entre conselhos nacionais. In: SOUTO, Anna Luiza; PAZ, Rosângela. (Orgs.). Novas lentes sobre a participação: utopias, agendas e desafios. São Paulo: Instituto Pólis, 2012.

NOGUEIRA NETO, Wanderlino. Por um sistema de promoção e proteção dos direitos humanos de crianças e adolescentes. Serviço Social e Sociedade, São Paulo, ano XXVI, n. 83, p. 5-29, 2005.

PONTUAL, Pedro de Carvalho. Desafios à construção da democracia participativa no Brasil: a prática dos conselhos de gestão das políticas públicas. Revista Soberania Popular, São Paulo, Ano I, n. 1, p. 160-185, dez. 2008. Disponível em: < http://polis.org.br/publicacoes/desafios-aconstrucao-da-democracia-participativa-no-brasil-a-pratica-dos-conselhos-de-gestao-das-politicas-publicas/>. Acesso em: 7 mar. 2014.

RAICHELIS, Raquel. Sistematização: os conselhos de gestão no contexto internacional. In: CARVALHO, Maria do Carmo A. A.; TEIXEIRA, Ana Cláudia C. (Orgs.). Conselhos gestores de políticas públicas. São Paulo: Instituto Pólis, 2000.

SANTOS, Benedito Rodrigues dos. Conselhos de direitos da criança e do adolescente, produção acadêmica e políticas públicas: por uma concentração de agendas. In: SOUZA FILHO, Rodrigo de; SANTOS, Benedito Rodrigues dos; DURIGUETTO, Maria Lúcia. (Orgs.). Conselhos dos direitos: desafios teóricos e práticos das experiências de democratização no campo da criança e do adolescente. Juiz de Fora: Ed. UFJF, 2012.

SUGUIHIRO, Vera Lucia Tieko. Conselhos de direitos: caminho de sua consolidação. Serviço Social em Revista, Londrina, v. 3, p. 9-26, 2000. 


\section{temporalis}

TEIXEIRA, Elenaldo Celso. Sistematização: efetividade e eficácia dos conselhos. In: CARVALHO, Maria do Carmo A. A.; TEIXEIRA, Ana Cláudia C. (Orgs.). Conselhos gestores de políticas públicas. São Paulo: Instituto Pólis, 2000. 


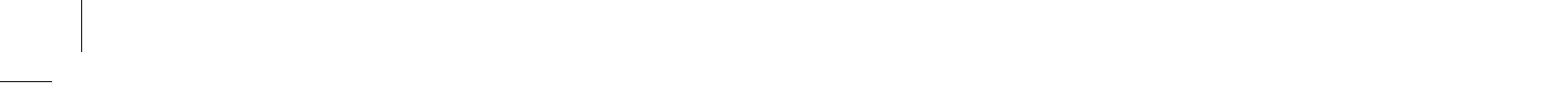

